\title{
Nitrogen cycle and particulate matter fluxes in the Indian Ocean subtropical gyre
}

Natalie C. Harms ${ }^{1 *}$, Niko Lahajnar ${ }^{1}$, Birgit

Gaye $^{1}$, Ulrich Schwarz-Schampera ${ }^{2}$ and

Kay-Christian Emeis ${ }^{1,3}$

${ }^{1}$ Institute of Geology, Universität Hamburg, Hamburg, 20146,

Germany, (*correspondence: natalie.harms@uni-

hamburg.de; niko.lahajnar@uni-hamburg.de,

birgit.gaye@uni-hamburg.de, kay.emeis@uni-

hamburg.de)

${ }^{2}$ Federal Institute for Geosciences and Natural Resources

(BGR), Hannover, 30655, Germany (Ulrich.Schwarz-

Schampera@bgr.de)

${ }^{3}$ Helmholtz-Zentrum Geesthacht (HZG), Institute for Coastal Research, Geesthacht, 21502, Germany

Oligotrophic subtropical gyres cover $\sim 75 \%$ of the ocean's surface and are predicted to expand under global warming and thus will become even more important for global marine nitrogen and carbon cycles. Consequently, it is essential to study $\mathrm{N}$-cycle processes and organic carbon fluxes to the deep ocean. The oligotrophic Indian Ocean subtropical gyre (IOSG) is one of the least explored ocean regions. Our investigations provide new field data on the nutrient distribution, its isotopic composition and on sinking particulate matter fluxes. Nutrient distribution in the IOSG are predominantly influenced by the typical flow-system of subtropical gyres leading to deep thermoclines, pycnoclines and nutriclines in the centre and thus form strongly stratified and nutrient-depleted surface waters. First, we demonstrate water mass distribution based on measurements of physical parameters. Combined with nutrient and isotopic data we verify nitrogen sources and transformation processes in the IOSG and across its boundaries. We find that nutrient distribution and the nitrate isotopic composition are affected by water masses of antarctic and subantarctic origin converging and mixing with water masses from the southern equatorial Indian Ocean and the Arabian Sea. In a second step, first sediment trap based data on sinking particulate matter fluxes provide new information on the nature of sinking organic matter, its controlling factors and on regional and temporal gyre variabilities. Due to the nutrient limited conditions in the IOSG we found lowest ever recorded particulate organic carbon fluxes world-wide. 